\title{
Scientific and Technological Innovation and Enterprise Sustainable Development Strategy Research
}

\author{
Henning Vochozka \\ Leipzig University, Leipzig, Germany.
}

How to cite this paper: Henning Vochozka. (2021) Scientific and Technological Innovation and Enterprise Sustainable Development Strategy Research. Advance in Sustainability, 1(1), 22-27.

DOI: $10.26855 /$ as.2021.07.005

Received: June 5, 2021

Accepted: June 30, 2021

Published: July 14, 2021

*Corresponding author: Henning Vochozka, Leipzig University, Leipzig, Germany.

\begin{abstract}
In today's big market environment, a variety of enterprises like bamboo shoots after a spring rain, no doubt intensified the competition between enterprises, but also for the development of enterprises has brought a greater threat. Similar enterprises have fierce competition in talent, or in scientific and technological innovation and so on. At German companies, known for their engineering skills, innovation and entrepreneurship are more related to manufacturing. Unlike their American counterparts, German companies are more cautious about their innovation models, assessing the sustainability and economics of their innovations in a comprehensive way, rather than overturning them all at once. However, what is the correct understanding of scientific and technological innovation? What is the connotation of enterprise sustainable development? How to deal with the relationship between the two? This paper will discuss these issues, put forward some ideas of the author, based on scientific and technological innovation, to explore the sustainable development of enterprises.
\end{abstract}

\section{Keywords}

Scientific and Technological Innovation, Enterprise, Sustainable Development, The Economic Development

\section{Introduction}

As is known to all, Germany is a leading manufacturing power and the author of the concept of Industry 4.0. In the manufacturing industry, especially in the field of intelligent manufacturing, Germany has a large number of world-class competitive enterprises, whose products and innovation capabilities are the first in the world, which is also the core strength of "German-style innovation". For the sustainable development of enterprises, scientific and technological innovation is very important. Only by combining the two, can enterprises prosper and develop permanently. We will discuss the scientific and technological innovation and the sustainable development of enterprises, discuss its basic connotation, existing problems and measures, so as to help scientific and technological innovation and achieve sustainable development of enterprises and promote economic prosperity and development.

\section{The connotation of scientific and technological innovation}

Scientific and technological innovation plays an important role in all aspects, which not only helps to promote the transformation of society, but also helps to transform nature. At the same time, scientific and technological innovation can also make human beings get further development, facilitate people's life, and make people enjoy life better. As far as science and tech- 
nology innovation itself is concerned, there are both narrow sense and broad sense of science and technology innovation. In the narrow sense, scientific and technological innovation refers to the improvement of labor objects and labor tools in the field of production by reforming engineering technology, so as to improve the efficiency and quality of production and promote the development of economy and society. The broad sense of science and technology includes a wide range of contents. It mainly refers to the improvement of production efficiency and the realization of related comprehensive benefits after the introduction of production. It refers to the residual value obtained after the subtraction of capital and labor factors. It includes not only scientific and technological innovation in a narrow sense, but also many aspects of society and policy, such as the update of equipment and technology and the improvement of workers' quality. This paper will take the construction enterprise as an example to carry on the in-depth analysis of it, based on the broad perspective of scientific and technological innovation and enterprise sustainable development. As far as science and technology innovation itself is concerned, it is a very complex process, which is composed of various contents and develops under their mutual influence.

\section{The meaning of sustainable development}

As early as in 1987, the United Nations committee has proposed project, to define the sustainable development, in the process of economic development, social benefit should be considered, not only satisfy the needs of their own, but also to meet the principles of sustainable development of environment, future generations also have related resources can be used, provide economic support for the happy life. Some people believe that in the process of sustainable development, ecological development should be the first priority, based on ecological harmony and integrity, reasonable development and use of natural resources, to promote the sustainable development of human living environment; In the process of economic development, we need to pay more attention to natural resources. On the premise of not damaging the quality of natural resources, we should vigorously develop the economy to maximize the profit without threatening the natural resources. In the process of production, clean technology should be used as much as possible to establish a non-polluting and low-energy technology system. In the process of economic development, we should adhere to the protection of natural resources as the premise, and at the same time to ensure that the environment and resources are in balance, to achieve sustainable development of enterprises. In the concept of sustainable development, it is necessary to pay attention to both short-term and long-term goals, as well as combine short-term and long-term interests, which is conducive to the sustainable development of enterprises. Sustainable development covers a wide range of areas, involving not only environment and resources, but also economy and society. We hope to achieve comprehensive and coordinated development in these areas. In this process, people need to strengthen their own awareness of environmental protection, improve the utilization rate of resources and energy utilization, so as to build a new mode of industrialization, so that the "low consumption, low pollution, high efficiency" of industry become a reality. To change the concept that modern people only pay attention to their own needs and ignore the living conditions of future generations in the process of economic development, this is conducive to promoting the overall reform of the society to a certain extent, and is opposed to only paying attention to partial and one-sided development in the process of development. In short, development is very important, development is also imperative, give up development, how to talk about sustainable? However, if sustainable, environmental protection and energy saving are not considered in the process of development, long-term development is bound to fail to become a reality. The sustainable development of the enterprise to consider the wider the range of not only need to pay attention to the recent development, but also need to pay attention to the enterprise long-term development, absolutely cannot penny-wise and pound foolish, give up the long-term interests of the enterprise, and for the development of the enterprise short-term, just meet the interests of the eyes, so difficult to realize the sustainable development of enterprises. On the other hand, sustainable development is also a concept of development that enterprises can always maintain a good state of development in the face of unpredictable and volatile market environment. The sustainable development of enterprises includes a wide range of contents, including not only the sustainable development of scale, benefit and production, but also the sustainable development of core competitiveness, culture, mechanism and science and technology.

\section{Historical investigation of scientific and technological innovation and sustainable development of enterprises}

The industrial revolution has greatly promoted the development of human society. This is a very special stage, which has a profound impact on scientific and technological innovation. This period was also the revolution of resource economy and agricultural economy, as well as the transformation of social economy. In view of the specific situation of the current world economic development, now is the era of knowledge economy, and compared with the past, the social thinking mode of human beings has also changed. Throughout the development of human society, the rapid social and economic changes are all related to science and technology. The industrial revolution of the 18th and 19th centuries was inseparable from science and technol- 
ogy, and the Internet age of the 21st century is closely related to science and technology. Enterprises and enterprise groups in the developed industrial countries are aware of the importance of science and technology first, found its revolutionary role in economic development, constantly study of science and technology, then create can improve production efficiency, adapted to modern society of science and technology, form their own core technology, promote the further development of the enterprise. In terms of the current world economic development, the relevant economic powers, led by the United States, have basically passed the peak period of industrialization and now most of them have entered the era of knowledge economy. In Europe and the United States in the long-term development of the market economy, in order to obtain the biggest economic benefits, better participate in market competition, they have been to scientific and technological innovation as a key link for the sustainable development of enterprises, in the 19th century to the 20th century, the enterprise through the establishment of technical center and so on, through the integration of resources such as market, economy, technology, constantly on product innovation, research and development from Unique products and technologies with core competitiveness, thus dominating the market. World-famous companies such as Siemens, Bell, and later Microsoft, all focused on scientific and technological innovation, thus achieving sustainable development of their enterprises. Therefore, whether it is based on history, reality, theory or practice, for the development of enterprises, scientific and technological innovation is particularly critical and plays a decisive role in the sustainable development of an enterprise. Scientific and technological innovation can best reflect the strength of an enterprise, and it is also the technical support of an enterprise, which attracts much attention in large enterprises.

\section{The relationship and role of scientific and technological innovation in sustainable development of enterprises}

\subsection{Relationship between scientific and technological innovation and sustainable development of enterprises}

For an enterprise, scientific and technological innovation is very important, but in terms of the nature of scientific and technological innovation and the sustainable development of enterprises, they have the essence of similarity, both adhere to the development as the center; pay attention to the development of low energy consumption, sustainable development; Based on the whole, pay attention to the harmonious development; The goal is sustainable development. In business management, enterprises tend to equate sustainable development with scientific and technological innovation, so as to realize the sustainable and long-term development of modern enterprises. Sustainable development cannot be separated from the sustainable development of science and technology. Scientific and technological innovation is the basis of sustainable development. The two are complementary and inseparable. Therefore, for modern enterprises, whether it is the sustainable development of enterprise production or the progress of enterprise culture, the realization of all aspects is closely related to scientific and technological innovation. In a word, the sustainable development of enterprises is very complicated. Without excellent scientific and technological strength, it is difficult to achieve the sustainable development of enterprises. At the same time, if there is no emphasis on scientific and technological innovation, the sustainable development can only become a fantasy. Thus, it can be seen that the importance of the combination of the two is absolutely inseparable. Since the economic development of today tends to be in a virtuous cycle stage, with the gradual economic development and the gradual increase of social capital, social capital will react on the economic development and promote the development of various industries. In this process, the development of this industry has tended to be saturated, and scientific and technological innovation is necessary, so as to improve the quality on the basis of guaranteeing the quantity, increase the competitive advantage of enterprises, and promote the development of enterprises. The development here refers to long-term development, sustainable development and sustainable development, and this development is in essence closely related to scientific and technological innovation. The two cannot be separated and develop together.

\subsection{The role of scientific and technological innovation in sustainable development of enterprises}

In modern enterprises, in order to promote economic development, enterprises will invest a lot of production factors, including human, financial, material, but also management. Scientific and technological innovation can promote the adjustment and upgrading of the industrial structure of enterprises and form the unique industrial structure by making reasonable use of these aspects. Through the correct use of scientific and technological innovation, it is beneficial to improve the production efficiency. But at the same time, technological innovation comes at a cost. In order to provide a better development path for enterprises and realize the low emission, low pollution, low energy consumption and high efficiency of enterprise production, it is necessary to realize the sustainable development of enterprises based on scientific and technological innovation. Scientific and technological innovation can not only promote the sustainable development of enterprises through some direct factors, but also indirectly affect the sustainable development of economy through some related factors. 


\section{Path analysis of sustainable development of enterprises}

\subsection{Correct understanding of scientific and technological innovation}

For an enterprise that wants to achieve sustainable development, it is necessary to have a correct understanding of scientific and technological innovation. Only when it correctly recognizes the importance of scientific and technological innovation can it be willing to spend time and energy on scientific and technological innovation, so as to enhance its competitive advantage based on scientific and technological innovation. Leaders of enterprises can give lectures on scientific and technological innovation to make the management realize the necessity of scientific and technological innovation, and take scientific and technological innovation as the core in their work to carry out related work and realize the sustainable development of enterprises. In addition, corporate leaders can also incorporate scientific and technological innovation into corporate culture, constantly edify the thoughts of employees, let them know the importance of scientific and technological innovation, imperceptibly influence employees, so that they pay attention to scientific and technological innovation. As an export powerhouse, German companies face global competition and innovation is more about improving manufacturing quality than creating concepts or financial arbitrage. A steady focus on areas and markets they know well, and a huge investment in R\&D and upgrading, is also how many German companies survive. Therefore, taking the enterprise as the main body of innovation and realizing the innovation goal with the product has become the prominent feature of "German innovation". Therefore, innovation activities can be quickly transformed into market benefits, and further promote independent innovation of enterprises, forming a virtuous circle. Such a model is unique even in the developed world.

\subsection{Introduction and training of outstanding scientific research personnel}

In science and technology innovation, talent is very critical. Although scientific and technological innovation requires the use of a large number of equipment and instruments, but if there are no excellent scientific research personnel, these instruments will only become high-end rotten copper and scrap iron, difficult to put into practical use. Therefore, in the process of operation and development, enterprises should correctly recognize the role of excellent scientific research talents, and recruit and introduce excellent scientific research talents to universities, so as to provide excellent talent reserve for enterprises' scientific and technological innovation. In addition, enterprises can also carry out special training for existing employees, stipulate the service period, improve the technical ability of employees, and train outstanding scientific research talents internally, so as to promote the further development of scientific and technological innovation and realize the sustainable development of enterprises.

\subsection{Improve the scientific research capacity of enterprises}

In science and technology innovation enterprise, the enterprise of scientific research ability is very important, not only refers to the enterprises with excellent scientific research talents, also need good science and technology innovation business atmosphere, and also be fitted with the corresponding equipment, so that is conducive to the further development of the enterprise technology innovation, promote the scientific research ability of the enterprise. Although excellent scientific research talents are very important in enterprise scientific and technological innovation, the most important thing is the enterprise itself. Therefore in the process of enterprise technology innovation, the enterprise should build a team, scientific and reasonable plan, to scientific and technological innovation, constantly raise the scientific and technological innovation ability of the enterprise, even a good scientific research personnel loss situation, also can make sure the enterprise can timely introduction of talent, through the good scientific research environment to promote the further development of science and technology innovation.

\subsection{Pay attention to the combination of scientific and technological innovation and production practice}

For enterprises, the most important thing is to achieve economic benefits, to achieve the maximum economic benefits. Although scientific and technological innovation is very important for the sustainable development of enterprises, in essence, technological innovation is behind the economic development of enterprises and the maximization of corporate profits. Therefore, scientific and technological innovation is not for the sake of scientific and technological innovation itself, but for the economic interests of enterprises. Therefore, in enterprises, we should not only talk about scientific and technological innovation, without talking about profit, economy and production practice. This is obviously contrary to the goal of scientific and technological innovation of enterprises, and it is difficult to achieve sustainable development of enterprises. In scientific and technological innovation, it is necessary to combine science and technology with production practice, so that scientific and technological innovation can be truly applied in production practice, improve the quality and efficiency of production, and promote its step-by-step development. In order to reduce the resistance in this link, the enterprise should arrange relevant scientific and technological personnel to enter the grass-roots level, understand the relevant process, and carry out scientific 
and technological innovation on this basis, so that the scientific and technological innovation can be combined with production practice, form the core competitiveness of the enterprise, and realize the sustainable development of the enterprise. The German government has also invested a lot of energy in helping companies cope with the changing times and focus on the future. As early as 2006, the German government promoted a "high-tech strategy" as a national will. Under the latest strategy, six more priority areas have been identified for development: digital economy and society, sustainable economy and energy, innovative working environment, healthy living, intelligent transportation and citizen safety. These areas are also the current challenges and weaknesses of German innovation, especially the digital economy. Germany's digital capacity ranks only 16th in the world, and its mobile broadband and high-speed optical fiber penetration rate ranks outside 50 in the world. Due to Germany's conservatism in this field, the progress in aspects such as autonomous driving and artificial intelligence is slow, and SMEs are even less sensitive to and capable of transformation in the ever-changing technological environment. Therefore, the German government has launched a series of innovation support projects for SMEs to help them meet the opportunities and challenges brought about by digitalization, globalization and value chain remodeling through policy encouragement and financial support.

\subsection{Set long-term goals}

For an enterprise to achieve sustainable development, long-term goals are essential. One step at a time, the same is true of business development. Therefore, enterprises should make long-term goals based on scientific and technological innovation, incorporate scientific and technological innovation into their strategic goals, and gradually promote scientific and technological innovation to become a reality. Enterprises in the process of setting goals, it is necessary to fully oneself circumstance analysis, at the same time, attach importance to the role of science and technology innovation, based on scientific and technological innovation in the long-term planning, comprehensive consideration of inputs such as manpower, financial resources, pay attention to the specific situation of the calculation of output and input, as far as possible ensure the input is less than the output, laborious scientific and technological innovation can make the enterprise achieve real profit, it not only helps to enhance the core competitive advantage of the enterprise, but also can maximize the economic benefits of the enterprise, so that the enterprise has enough funds to expand the scale of production and promote the long-term development of the enterprise. In response, Germany has added new "exist" programs ("exist-Founder Scholarship" and "exist-Transfer of Scientific Research Achievements" and other programs), Invest-Venture Capital Subsidies, and "Biotechnology-Entrepreneurs Offensive” programs to encourage the establishment of more innovative start-ups. In addition, in order to promote the balanced development of region innovation, through innovation ability "eastern" plan to support industrial research organization in the non-profit research project, "offensive" enterprise zones-innovation plan began to form in the east with the international competitiveness of science and technology, economic base and a cluster, "20" inter-district research plans to establish and consolidate cooperation, the increase of capability of science and technology and economy of the east area.

\section{Conclusion}

For the development of an enterprise, scientific and technological innovation and sustainable development are very important, the two complement each other and cannot be separated. For the sustainable development of an enterprise, scientific and technological innovation is the prerequisite, and it is also the core content to achieve the sustainable development of an enterprise. Therefore, in the process of enterprise development, in order to achieve their own sustainable development, in order to achieve sustainable development, it is necessary to pay attention to scientific and technological innovation, take scientific and technological innovation as the core of enterprise development, and then realize the all-round development of the enterprise, to achieve the prosperity of the enterprise. From the point of view of the specific situation of enterprise science and technology innovation, it is not optimistic, there are various problems, such as the lack of excellent scientific research personnel, lack of correct understanding of science and technology innovation, this paper analyzes the actual situation of enterprise science and technology innovation, put forward the solution measures, to achieve the sustainable development of enterprises.

\section{References}

[1] Eco-efficiency and beyond: Towards the sustainable enterprise [M]. Routledge, 2017.

[2] Engelke, H., Mauksch, S., Darkow, I. L., et al. (2015). Opportunities for social enterprise in Germany-Evidence from an expert survey [J]. Technological Forecasting and Social Change, 2015, 90: 635-646.

[3] Chofreh, A. G., Goni, F. A., Klemeš, J. J. (2018). A roadmap for Sustainable Enterprise Resource Planning systems implementation (part III) [J]. Journal of cleaner Production, 2018, 174: 1325-1337.

[4] Mauksch, S. (2012). Beyond managerial rationality: exploring social enterprise in Germany [J]. Social Enterprise Journal, 2012. 
[5] Kasych, A., Vochozka, M. (2017). Theoretical and methodical principles of managing enterprise sustainable development [J].

[6] Skorobogatova, N. (2019). Sustainable development of an enterprise under industry 4.0 conditions[C]//2019 International conference on creative business for smart and sustainable growth (CREBUS). IEEE, 2019: 1-5.

[7] McRobbie, A. (2011). Re-thinking creative economy as radical social enterprise [J]. Variant, 2011, 41(Spring): 32-33. 